\title{
The Study of Customer Needs of Application-Based Online Transportation in Jakarta
}

\author{
D Tamara ${ }^{1}$, J P Gaspersz ${ }^{2}$, I K Silalahi ${ }^{3}$ \\ ${ }^{1,2,3}$ Executive in Strategic Management Program, Universitas Bina Nusantara, Jakarta, \\ Indonesia \\ ${ }^{1}$ dtamara@binus.edu, ${ }^{2}$ joyce.gaspersz@gmail.com, ${ }^{3}$ irennesilalahi@gmail.com
}

\begin{abstract}
The demand for application-based online transportation is increasing, especially for developing countries like Indonesia, especially capital city as Jakarta. This study investigates the reasons for a company to choose the application-based online transportation as their business transportation solution. Furthermore, this study examines the corporate needs and recommends solutions. The research was conducted through a survey of employees and corporate administration staff in Jakarta province. The result of this study finds that companies need a transparent pricing system, on time service, and safety for transportation online provider. The researcher also found that companies did use the transportation online as a substitute for traditional transportation. As there is still big untapped market, it is an interesting market opportunity for transportation online provider to increase their service quality in terms of price, cost and safety.
\end{abstract}

Keywords: Application-Based, Transportation, Companies Asymmetric

\section{INTRODUCTION}

The needs of online transportation is increasing in big cities around the world. However, the market is still dominated by conventional transportation companies. In Indonesia, there are several major transportation such as PT Adi Sarana Armada, PT Bluebird, PT Expressindo, and others.

On the other hand, based on report PEW Research Center, a number of starts-up online services have developed in recent years, and ready to reshape, change the way people move around in their daily life [1]. Some of these services offer easiness from a click of a mouse or touch their smartphone apps. Others promote the speed to connect communities, offices using collaborative platforms and offer as well sharing economies through their ecosystem and network. Examples of these transportation services are Gojek, Grab, Uber, Lynx and so on.

This study investigates the key triggers for companies to use an application-based online transportation software as their business transportation solutions, what the behaviors of corporate users are, and what strategies are implemented to meet their expectations. 


\section{LITERATURE REVIEW}

\subsection{Corporate Behavior and Expectations}

In a research article it is stated that the differences in how individual consumers and companies purchase a product is characterized as follows 1) Careful consideration, 2) Formal purchasing procedures and a procurement process, 3) cost analysis of transaction, and 4) Personal guidance of a sales representative is needed [2].

\subsubsection{Careful Consideration}

A company tends to do some research before buying a product. Starting with a selection of several products to be compared, then, a candidate will be chosen based on the brand, product functionality, service quality, price, and total cost.

The brand is of particular importance for a B2B's buying decision. It secures the company when making a decision to use a recognized brand. It is an assurance for the company to deal with a well-known brand, as it will secure and settle in the case where problems occurs.

\subsubsection{Formal Purchasing Procedures and the Procurement Process}

The company will then have a set of procedures and a procurement process in order to acquire a new partner. The company needs to ensure that the third party can provide the expected services. Therefore, a compliance list needs to be provided by a third party. In the compliance list, much information is catered such as the payment method, service level agreement, and variety of services.

\subsubsection{A cost Analysis is Required Including the Cost of a Transaction.}

Another important factor is also to reduce costs. With regard to costs, employees as their respondents emphasize that they prefer to have a transparent pricing system and offer low prices consistently with excellent service. Employees accept differences in prices for different customers and even require differentiation; they demand payments for their loyalty in the form of good prices or special handling facilities.

\subsubsection{Personal Guidance of a Sales Representative is Needed.}

The company usually needs more guidance from a sales representative to provide it with a company overview and product knowledge. The company also expects a fast response and full-context of its requirements. Therefore, having a sales representative is irreplaceable.

All of these results combined confirm that cost and pricing, service differentiation, brand awareness, and perception play an important role in winning the corporate and employee market.

\subsection{Marketing for Corporate Users}

The Internet era has built opportunities. It has changed B2B's buying behavior [3]. Through the Internet, buyers are able to get knowledge easily. Therefore, they become more knowledgeable, which leads them to become more impatient. The challenge, on the other hand, is that marketing activities for B2B sometimes may not provide management with insights. As a result, other initiatives are required in making strategic decisions. 
The success of Alibaba, as the largest online and mobile company in the world, emphasizes high quality service at a reasonable price with various business marketing channels and promotions [4].

Marketing orientation and business performance is an important research stream The proposition of this stream focus on organization that have market oriented has better outcomes than non-market oriented companies [5]. The apps-based companies such as ride-hailing transportation is also should apply this strategy to be competitive in the market [6]. Furthermore, as much as a company wants to use social media as its marketing channel, it is only useful for soft-sell marketing such as to develop the brand image and may also be used in market research, business networking, and possibly sales prospecting [6]. However, the relation between the marketing take-up rate and usage consumption is not discussed in the literature.

The sales representative is also irreplaceable and still need for the apps-based online transportation service. This could be one of a service differentiation among well-known brand corporation [2].

Based on the findings of the literature review related to the hypothesis, this research focuses on the key triggers for a company to use an app-based online transportation software as its business transportation solution.

To address the cost concern and service differentiation, a deep understanding of corporate needs is required. It is necessary to examine what aspects a corporation considers when choosing a transportation service and the priorities between those aspects, on what occasions a company needs business transportation, if there is any frequent usage, the travel distance, and if there any specific needs for the vehicle type.

To address the brand image and perception, a response from employee users regarding an app-based online transportation brand is required to measure the brand perception and onground performance.

\subsection{Application-Based Online Transportation}

Taxi drivers are required to obtain an occupational license in order to transport passengers, and drivers are restricted from picking up passengers outside of the jurisdictions that issue their licenses (in some jurisdictions). Meanwhile, for application-based online transportation, the companies offer transportation services to customers through online booking services. Application-based online transportation is basically an application that matches orders coming from people who need a ride with drivers who are willing to provide the service using their personal vehicles. This is different with conventional transportation such as a taxi with a yellow-plate car as public transportation. For conventional transportation, users hail a vehicle by the street side or submit an order to a call center. A research describes how applicationbased online transportation disrupts the conventional taxi business [7]

Furthermore, the services are now evolving in Indonesia, especially in Jakarta. The service users no longer use the services for personal reasons only, but also for corporate matters, such as document and package delivery. A corporate user can be defined as a consumer who uses a transportation service for business transportation on behalf of the company, and the service is done to support the company's activities. This paper will discuss the business transportation system using an application-based online transportation software.

Business transportation means transportation that is required by employees to support their businesses. It is normally decided by each company; however, in general it can be classified as transportation for business meetings, business trips, late-night shifts, and company events. 


\section{METHOD}

The working population in Jakarta is 4,7 million people. The target sample is corporate and individual who is employee in a company. Total sample taken is 100 respondent with 90 is employees and 10 is corporate administration. The corporate administration can be HR staff which has authority to decide the choose the transportation solution in the company.

Questionnaires were distributed through convenience random sampling in an online form with two categories for the respondent profile:

1. Corporate administration staff in organizations that currently subscribe to a transportation solution/taxi service for their employees or organizations that express interest in using an application-based online transportation service for employees.

2. Employees that use an application-based online transportation service.

Corporate administration staffs are employees who are responsible for choosing and selecting transportation services that will be used by the company for operational activities. The stakeholders are usually decision makers from the General Affairs Division, Human Resources, Procurement, or Finance.

Employees are employed by a company and transported between the office and other places, and vice versa, for business purposes. It is necessary to understand the requirements from both profiles to be certain about the user profiles; the requirements, behavior, and expectations from the employees' perspectives as well as the requirements and considerations from the corporate administration staff in a company in order to make decisions about a company's transportation.

\subsection{Study Hypothesis}

This research was designed to focus on understanding the market opportunity by spotting the key triggers for a company to use an application-based online transportation system as its business transportation solution. It is hypothesized that the following items play an important role in winning the corporate and employee market:

1. Market opportunity, in which employees and corporate administrative staff prefer a transparent pricing system and offer low prices consistently with excellent service.

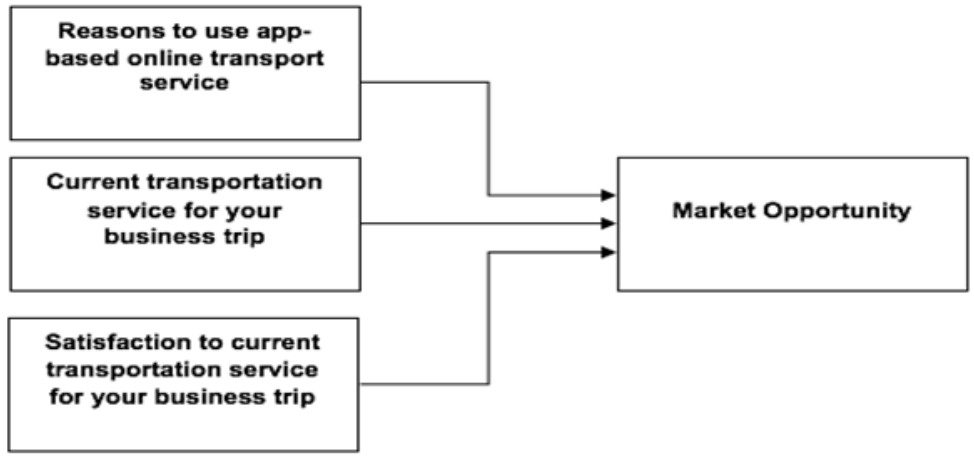

Figure 1. Market Opportunity.

2. Services, in which employees and corporate administration staff value service time, personal relationships, and employee partnerships. 


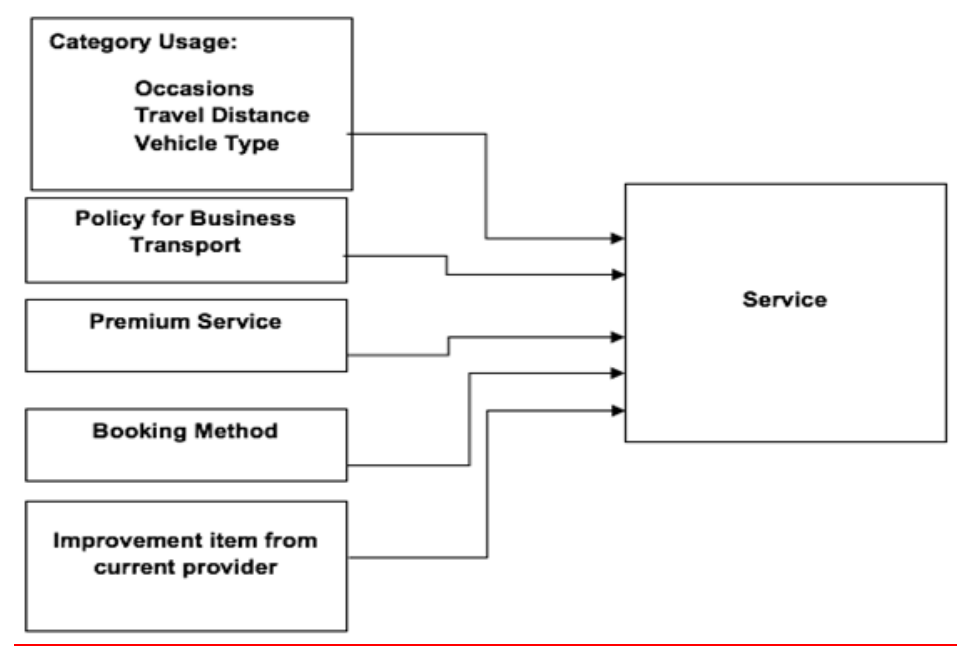

Figure 2. Services.

3. Marketing, in which the brand and awareness are of particular importance for a company.

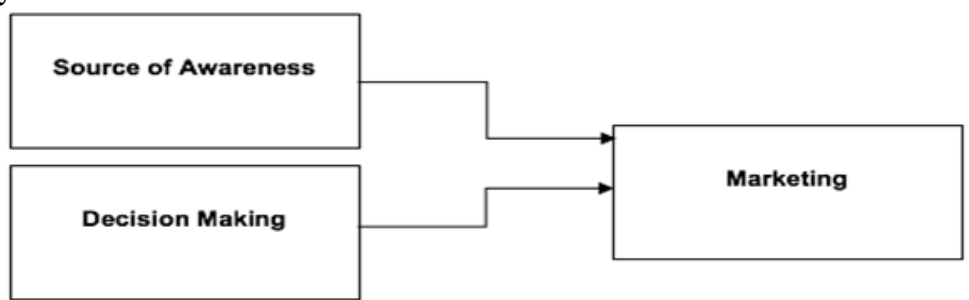

Figure 3. Marketing.

Information on cost and pricing, service differentiation, and brand awareness was collected through an online form using a structured questionnaire. The emphasis was to understand the wants and values of a corporate transportation solution, and various variables as stated in the following chart were collected. The list of variables is presented in Table 1. The operationalization of variables is shown in Table 2.

Table 1. Variables used in survey.

\begin{tabular}{lc}
\hline \multicolumn{1}{c}{ Variables } & $\begin{array}{c}\text { Scale of } \\
\text { Variables }\end{array}$ \\
\hline Category usage: Occasions & Nominal \\
Category usage: Travel distance & Nominal \\
Category usage: Vehicle type & Nominal \\
Policy for business transportation & Nominal \\
Premium service & Nominal \\
Booking method & Nominal \\
Reasons to use an app-based online transportation service & Nominal \\
Current transportation service for your business trip & Nominal \\
Satisfaction of the current transportation service for your & Ordinal \\
\hline
\end{tabular}


business trip

Improvement item from the current provider

Nominal

Source of awareness

Nominal

Decision making

Nominal

Table 2. Variables \& Measurement Attributes.

\begin{tabular}{|c|c|}
\hline Questions & Measurement Attributes \\
\hline $\begin{array}{l}\text { Category usage: Occasions } \\
\text { Corporate administrative staff perspective: } \\
\text { Which of the following occasions does your } \\
\text { company need business transportation } \\
\text { services mostly for? } \\
\text { Employee perspective: } \\
\text { Which of the following occasions do you need } \\
\text { business transportation services mostly for? }\end{array}$ & $\begin{array}{ll}\text { - } & \text { Short on time } \\
\text { - } & \text { When other transportation modes } \\
\text { - } & \text { Bad weather } \\
\text { - } & \text { Parking not available } \\
\text { - Nothing in particular } \\
\text { - Other } \\
\text { - Short on time } \\
\text { - When other transportation modes } \\
\text { - } \quad \text { are not available } \\
\text { - Parking not available } \\
\text { - Nothing in particular } \\
\text { Other }\end{array}$ \\
\hline $\begin{array}{l}\text { Category usage: Travel distance } \\
\text { Corporate administrative staff perspective: } \\
\text { What is the distance you normally travel when } \\
\text { using a business transportation service? } \\
\text { Employee perspective: } \\
\text { What is the distance you normally travel when } \\
\text { using a business transportation service? }\end{array}$ & $\begin{array}{ll}\text { - } & \text { Short }(<5 \mathrm{~km}) \\
\text { - } & \text { Medium }(5-10 \mathrm{~km}) \\
\text { - } & \text { Long }(>10 \mathrm{~km}) \\
\text { - } & \text { Short }(<5 \mathrm{~km}) \\
\text { - } & \text { Medium }(5-10 \mathrm{~km}) \\
\text { - } & \operatorname{Long}(>10 \mathrm{~km})\end{array}$ \\
\hline Category usage: Vehicle type & \\
\hline $\begin{array}{l}\text { Corporate administrative staff perspective: } \\
\text { What type of vehicle does your company } \\
\text { normally use for business transportation } \\
\text { services? } \\
\text { Employee perspective: } \\
\text { What type of car do you normally use for } \\
\text { business transportation services? }\end{array}$ & $\begin{array}{l}\text { - Standard MPV (Avanza, Xenia) } \\
\text { - Medium Standard MPV (Innova, } \\
\text { - Perena) } \\
\text { Premium (Alphard, Mercedes, } \\
\text { - Camry) } \\
\text { - Standard MPV (Avanza, Xenia) } \\
\text { - Medium Standard MPV (Innova, } \\
\text { Serena) } \\
\text { - Premium (Alphard, Mercedes, } \\
\text { Camry) }\end{array}$ \\
\hline
\end{tabular}

Policy for business transportation 
Corporate administrative staff perspective: Which business transportation policy works for your company?

Employee perspective:

Which policy for business transportation in your company works for you?

\section{Premium service}

Corporate administration staff perspective: What premium services would you like to have as corporate clients?

Employee perspective:

What premium services would you like to have as corporate clients?
- Postpaid. Monthly bills with a bank transfer

- Postpaid. Monthly bills with a credit card

- Prepaid with a bank transfer

- Reimbursement (employee pays in cash for each transaction and is reimbursed by the company)

- Cashless, the company pays for the ride

- Reimbursement (employee pays first and is reimbursed by the company)

- Higher quality vehicles

- Priority allocation in booking

- Customer service hotline

- Administration staff booking

- Integration with the existing system

- Other

- Higher quality vehicles

- Priority allocation in booking

- Customer service hotline

- Administration staff booking

- Integration with the existing system

- Other

\section{Booking method}

Corporate administration staff perspective:

Which of the following booking methods would you prefer to get transportation services?

Employee perspective:

Which of the following booking methods would you prefer to get transportation services?
- Call
- $S M S$
- App
- Website
- Email
- Hail by the street side
- Other
- Call
- $S M S$
- App
- Website
- Email
- Hail by the street side
- Other

Reasons to use an app-based online transportation service

Corporate administration staff perspective:

What are the reasons that would make your company use an online transportation service for a business transportation policy? Please
- Fixed \& transparent price

- Cheaper than normal transportation mode

- Better ride experience 
select the top three reasons and rank them accordingly.

\section{Employee perspective:}

What are the reasons that would make your company use an online transportation service for a business transportation policy? Please select the top three reasons and rank them accordingly.

- Variety of vehicle options

- Easy to use platform which allows consolidated bills

- Support monthly bills, corporate/personal credit card

- Attractive promotion

- Recommended or referred by employees or other companies

- Dedicated account manager

- Positive brand image

- Fixed \& transparent price

- Cheaper than normal transportation mode

- Better ride experience

- Variety of vehicle options

- Easy to use platform which allows consolidated bills

- Support monthly bills, corporate/personal credit card

- Attractive promotion

- Recommended or referred by employees or other companies

- Dedicated account manager

- Positive brand image

\section{Current transportation service for your business trip}

Corporate administration staff perspective:

Which of the following services does your company use THE MOST for business transportation purposes?

Employee Perspective:

Which of the following services do you use THE MOST for business transportation purposes?
- Online transportation:

$$
\text { - Grab }
$$

- Taxi

- Blue Bird physical voucher

- Blue Bird e-Voucher

- Dedicated cars:

- Car rental

- Own company car

- Online transportation:

$$
\text { - Grab }
$$

- Taxi

- Blue Bird physical voucher

- Blue Bird e-Voucher

- Dedicated cars:

- Car rental

- Own company car

\section{Satisfaction of the current transportation service for your business trip}

\section{Company \& employee perspective:}

On a scale of 0 to 10, how satisfied are you 0 (not satisfied at all) to with the online/offline transportation service? 10 (extremely satisfied) 
Improvement item from the current provider Company \& employee perspective:

What do you want to improve with the online/offline transportation service?
Online:

- Reliable - car allocation

- Cost reduction

- Better driver service

- Dedicated account manager

- Payment method

- Other

Offline:

- Heard other colleagues/ employees/ companies had a bad experience while using the online transportation service

- Not safe to use

- Don't want to reveal my personal information

- Hard to get a car from my company's location

- Hard to get a car during peak hours

- Booking through the app is complicated

- Other

\section{Source of awareness}

Company \& employee perspective:

Which of the following sources do you prefer to know about for business transportation solutions?
- Social media ads

- Ads on other sites apart from social media

- Heard from friends

- Friends share information on social media

- Ads on car or in car

- Read information on a website

- Info through email

- In-app notification

- Other

\section{Decision making}

Company \& employee perspective:

Which of the following is important in your decision-making when considering an ondemand online transport app for your business transportation service?

- $\quad$ Best price offers

- Safety

- Excellent customer service

- Allows $100 \%$ allocation

- Other 


\section{RESULT AND DISCUSSION}

\subsection{Results}

The research was conducted with a data survey of consumer respondents, targeted to employees and corporate administration staff in organizations in Jakarta. From the survey results, $63 \%$ of employees and $37 \%$ of corporate administration staff participated in the survey with a total of 105 respondents.

To follow the framework, below are the metrics that can be summarized from the survey.

\subsubsection{Market Opportunity}

\section{a. Reasons to Use an App-Based Online Transportation Service}

It is consistent both from employee and corporate administration staff perspectives that the top reasons to use app-based online transportation services are:

1) Fixed and transparent prices, as about $33 \%$ of the respondents said that having fixed and transparent prices is the top reason to use an app-based online transportation service.

2) Fares are considered cheaper than normal transportation, as about $30 \%$ of respondents said that fares were the other reason being considered in using an appbased online transportation service.

\section{b. Current Transportation Service for Your Business Trip}

- Based on the corporate administration staff response, it is clear that companies use app-based online transportation to support their business trips. However, there are opportunities to tap companies which are still using taxis, car rentals, and companyowned cars to support their business transportation. The responses are as follows:

- $47.1 \%$ of respondents said their companies use app-based online transportation

- $\quad 29.4 \%$ use taxis

- $\quad 11.8 \%$ use car rentals

- $11.7 \%$ of respondents used their own cars to support their business transportation

- From an employee perspective, it is equally shared between offline and online transportation. On average, $22 \%$ of respondents said that they use either companyowned cars, taxis, or app-based online transportation.

\section{c. Satisfaction of Current Transportation Service for Your Business Trip}

Based on the satisfaction, there are gaps in which app-based online transportation can fill them as a room for improvement, considering that satisfaction for app-based online transportation is still moderate, while for offline transportation service it is slightly higher compared with the online transportation. 


\subsubsection{Service to Provide}

\section{a. Category Usage}

- Occasions

It is consistent both from a corporate administration staff perspective and an employee perspective that business transportation is required anytime when necessary. This is followed with the point when other transportation modes are not available and when they are short on time.

- Travel distance

It is consistent both from a corporate administrative staff perspective and an employee perspective that business transportation is mostly needed for medium trips, with the definition of a trip distance being from $5-10 \mathrm{~km}$.

- Vehicle type

It is consistent both from a corporate administrative staff perspective and an employee perspective that the type of vehicle mostly needed for business transportation is a standard MPV, with the definition of a standard 6-seater MPV being similar to an Avanza or Xenia.

\section{b. Policy for Business Transportation}

There are two policies applied for business transportation in a company based on a corporate administrative staff perspective, which are as follows:

- Postpaid with a monthly billing method - bank transfer payment to the transportation provider

- Reimbursement method where a company allows employees to reimburse their business trips

However, from employees' perspective, a cashless ride where the company pays the fare to the transportation company is much more preferable.

\section{c. Premium Service}

It is consistent both from the corporate administration staff perspective and employee perspective that priority allocation for cars is the main service which they can consider as premium.

\section{d. Booking Method}

It is consistent both from a corporate administration staff perspective and an employee perspective that the majority of them prefer booking through an app. However, other than booking through an application, it is also convenient for them to book by calling a transportation company.

\section{e. Improvement Item to Support Your Business Trip}

For online transportation, the main service highlighted is to have a better driver service. The reason stated for online transportation is to improve the difficulties in getting transportation during peak hours. 


\subsubsection{Marketing}

\section{a. Source of Awareness}

There are three top sources that respondents are interested to know more information about business transportation solutions which are as follows:

- Referral from other colleagues

- Social media ads

- In-app notification

The responses to those channels is around $39-41 \%$.

\section{b. Decision Making}

The highest points for respondents to consider related to decision-making about choosing a transportation provider to support business transportation are safety and commercial aspects (cost \& pricing). Both have the same weightage at above $70 \%$.

\subsection{Discussion}

Based on the findings in the literature review, this research is designed to focus on understanding the market opportunities by determining the key triggers for a company to use an application-based online transportation system as their business transportation solution. It is hypothesized that the following items play an important role in winning the corporate and employee market:

\section{Market opportunity}

The survey results are aligned with the hypothesis that employees and corporate administration staff prefer a transparent pricing system and consistent low price offers with excellent service.

\section{Services}

The survey results reveal that service is highly important to support the categories of usage, payment policy, and ease of allocation. It is aligned with the hypothesis that employees and corporate administration staff value service time.

\section{Marketing}

It is hypothesized that brand and awareness are of particular importance for a company. Based on the survey, referrals, social media, and in-app notifications are the best channels to build awareness. Meanwhile, the brand perception expected is for safety and cost.

\section{CONCLUSION}

This paper examined the key triggers for a company to use an application-based online transportation system as a business transportation solution, the behavior of corporate users, and the strategies utilized to meet their expectations.

Based on the survey conducted, it can be seen that there are opportunities for an application-based online transportation service to provide transportation for corporate customers, as the main reason to use it is because it is transparent and has cheaper prices 
compared to conventional transportation. Furthermore, the survey indicated that corporate users already used application-based online transportation as their solution, but there are still markets to be tapped for users that are still using taxis or other transportation modes.

As for determining which services to provide to the corporate customer, careful consideration should be made for the selection of payment method, premium services, and booking method.

From the marketing side, an online transportation company should consider several channels which have been chosen by customers to get information regarding the online transportation services, which are from referrals, social media, and in-app notifications. Then for the final selection regarding what services should be selected, corporate customers will put greater consideration into two options, which are safety and commercial (cost \& pricing) aspects.

\section{REFERENCES}

[1] A. Smith, "Shared, Collaborative and On Demand, The New Digital Economy PEW," Res. Cent., 2016.

[2] M. Pawłowski and Z. Pastuszak, "B2B customer buying behavior,” Int. J. Synerg. Res., vol. 5, pp. 19-35, 2016.

[3] G. M. S. Chauhan and C. Anbalagan, "Strategy and trends in B2B business: Opportunities and challenges - a global prospective," IFSMRC AIJRM, vol. 2, no. 3, 2014.

[4] R. Yazdanifard and M. T. H. Li, "The review of Alibaba's online business marketing strategies which navigate them to present success," J. Business-to-bus. Mark., vol. 14, no. 7, pp. 32-40, 2014.

[5] S. Pulendran, R. Speed, and R. E. Widing, "Marketing planning, market orientation and business performance," Eur. J. Mark., vol. 37, no. 3/4, pp. 476-497, Apr. 2003.

[6] R. Brennan and R. Croft, "The use of social media in B2B marketing and branding: An exploratory study," J. Cust. Behav., vol. 11, no. 2, pp. 101-115, Sep. 2012.

[7] J. Cramer and A. Krueger, "Disruptive Change in the Taxi Business: The Case of Uber," National Bureau of Economic Research, Cambridge, MA, Mar. 2016. 